\section{ACTUACIONES DE LAS VÍCTIMAS COMO SUJETOS PROCESALES EN EL NUEVO SISTEMA PENAL ACUSATORIO*}

\author{
Alvaro E. Márquez Cárdenas Ph. D. ${ }^{* *}$
}

Fecha de recepción: 8 de Octubre de 2010

Fecha de aceptación: 30 de Noviembre de 2010

Artículo Resultado de Proyecto de Investigación.

\section{Resumen}

Mediante sentencias de la Corte Constitucional se ha venido reconociendo y construyendo una serie de actuaciones procesales que las victimas pueden realizar en el proceso penal sin necesidad de postularse en el proceso mediante un apoderado, como sucedía en el proceso inquisitivo de la Ley 600. Este sistema procesal requería presentar una demanda de la parte civil para actuar a través de su apoderado, en el caso donde la víctima era la principal interesada en las resultas del proceso, buscando que se hiciera justicia y se le reconociera en últimas su derecho por el daño causado con el delito.

\section{Palabras clave}

Víctima, justicia restaurativa, derecho a la verdad, derecho a que se haga justicia, derecho

* El presente escrito es el resultado de la investigación denominada: "La Conciliación preprocesal en el nuevo sistema procesal acusatorio". Línea de investigación: Derecho penal. Centro de investigaciones de la Universidad Militar Nueva Granada.

** Abogado. Doctor en Derecho y Especialista en criminología, Universidad Complutense de Madrid, España. Master en Estudios Políticos, Universidad Javeriana, Colombia. Ex magistrado. Docente investigador-postgrados de la Facultad de Derecho de la Universidad Libre. Director Centro de investigaciones de la Universidad Militar Nueva Granada. Publicaciones: $L a$ Autoría Mediata en el Derecho Penal, La Delincuencia Económica y la Coautoría en Derecho penal. alvaro.marquez@, unimilitar.edu.co; marquez_alvaro@hotmail.com a la reparación, garantía de no repetición, actuación procesal, proceso penal, sistema acusatorio.

\section{PROCEEDINGS OF THE VICTIMS AS PROCEDURAL SUBJECTS IN THE NEW CRIMINAL LAW SYSTEM}

\begin{abstract}
By means of judgments of the Constitutional Court come recognizing and constructing a series of procedural actions that the victims it can realize in the penal process without need of be postulated in the process by means of a proxy, since it was happening in the inquisitive process of the law 600 . This procedural system was needing to sue for civil part to act across his proxy, in the case where the victim was the principal one interested in you them ensue from the process, looking that was doing justice to himself and his right was recognized in last by the hurt caused with of the crime.
\end{abstract}

\section{Key words}

Victim, restorative justice, right to the truth, right to which justice, right does to itself to the repair, guarantee of not repetition, procedural action, penal process, accusatory system.

\section{RESULTADOS}

\section{De los derechos de las victimas a la verdad, justicia y reparacion}

La Corte Constitucional ha construido una sólida y consistente jurisprudencia sobre el alcance constitucional de los derechos de las víctimas y perjudicados con las conductas punibles; en este acápite mencionamos los derechos de las victimas como sujetos procesales, entendiendo que ha sido superada esa consideración de tener a las víctimas como meros intervinientes. 
Si desde el punto de vista material la victima tiene el derecho a la verdad, a que se haga justicia y a la reparación, lo que se plantea en este capítulo es cómo puede hacer valer esos derechos en el proceso penal, es decir, qué actuaciones puede realizar para hacer efectivos sus derechos.

El derecho a la verdad ${ }^{1}$, es el derecho a que las víctimas puedan saber lo que realmente sucedió en un acontecimiento criminal no sólo en situaciones de conflicto armado, sino frente a cualquier delito ${ }^{2}$. La jurisprudencia Constitucional estimó el conjunto de principios para la protección y la promoción de los derechos humanos mediante la lucha contra la impunidad $^{3}$, e incorpora el derecho a la verdad: -el derecho inalienable a la verdad; - el deber de recordar; - el derecho de las víctimas a saber.

El primero, comporta el derecho de cada pueblo a conocer la verdad acerca de los acontecimientos sucedidos y las circunstancias que llevaron a la perpetración de los crímenes en un conflicto armado. El segundo, consiste en el conocimiento por un pueblo de la historia de su opresión como parte de su patrimonio, y por ello se deben adoptar medidas adecuadas en aras

AMNISTÍA INTERNACIONAL (S.F.). Manual Para La Acción, Desapariciones Forzadas y Homicidios Politicos: La Crisis de Los Derechos Humanos. EDAI. Madrid. p. 212.

2 Ver: Mendez, J. "Derecho a la verdad frente a las graves violaciones a los Derechos Humanos". En: ABREGU, Martín, et al (comp). La Aplicación de los Tratados sobre Derechos Humanos por los Tribunales Locales. Editorial Del Puerto. Buenos Aires. 1997. p. 231

3 Esta sistematización se apoya en el "Conjunto de Principios para la protección y promoción de los derechos humanos mediante la lucha contra la impunidad". Anexo del Informe final del Relator Especial acerca de la cuestión de la impunidad de los autores de violaciones de los derechos humanos. E/CN.4/Sub2/1997/20/Rev.1. Presentado a la Comisión de Derechos Humanos en 1998. Estos principios fueron actualizados por la experta independiente Diane Orentlicher, de acuerdo con informe E/CN. 4/2005/102, presentado a la Comisión de Derechos Humanos. del deber de recordar que incumbe al Estado. Y el tercero, determina que, independientemente de las acciones que las víctimas, así como sus familiares o allegados puedan entablar ante la justicia, tiene el derecho imprescriptible a conocer la verdad, acerca de las circunstancias en que se cometieron las violaciones, y en caso de fallecimiento o desaparición acerca de la suerte que corrió la víctima.

El derecho a la verdad presenta así una dimensión colectiva cuyo fin es "preservar del olvido a la memoria colectiva"4, y una dimensión individual cuya efectividad se realiza fundamentalmente en el ámbito judicial, a través del derecho de las víctimas a un recurso judicial efectivo, tal como lo ha reconocido la jurisprudencia de Corte Constitucional $^{5}$.

Proyectando estos principios en el ámbito nacional, la jurisprudencia constitucional ha determinado que el derecho de acceder a la verdad implica que las personas tienen derecho a conocer qué fue lo que realmente sucedió en su caso. La dignidad humana de una persona se ve afectada si se le priva de información que es vital para ella; el acceso a la verdad aparece así íntimamente ligado al respeto de la dignidad humana, a la memoria y a la imagen de la víctima ${ }^{6}$.

El derecho a que se haga justicia, en el derecho se relaciona con las garantías para las víctimas de los delitos que se derivan de unos correlativos deberes para las autoridades, que pueden sistematizarse así: (i) el deber del Estado de investigar y sancionar adecuadamente a los autores y partícipes de los delitos; (ii) el derecho de las víctimas a un recurso judicial efectivo;

4 Principio No. 2 del Conjunto de Principios para la protección y promoción de los derechos humanos mediante la lucha contra la impunidad.

5 Cfr. Entre otras las sentencias C-293 de 1995 y C-228 de 2002.

6 Cfr. Sentencias T-443 de 1994. MP. Eduardo Cifuentes Muñoz. C-293 de 1995. MP, Carlos Gaviria Díaz. 
(iii) el deber de respetar en todos los juicios las reglas del debido proceso ${ }^{7}$.

La jurisprudencia constitucional ha señalado el derecho de acceso a la justicia, que tiene como uno de sus componentes naturales el derecho a que se haga justicia. Este derecho involucra un verdadero derecho constitucional al proceso penal $^{8}$, y el derecho a participar en el proceso penal $^{9}$, por cuanto el derecho al proceso en el Estado democrático debe ser eminentemente participativo. Esta participación se expresa en

"que los familiares de la persona fallecida y sus representantes legales serán informados de las audiencias que se celebren, a las que tendrán acceso, así como a toda información pertinente a la investigación y tendrán derecho a presentar otras pruebas" $"$.

El derecho a la reparación integral del daño, es el derecho de reparación, conforme al derecho internacional contemporáneo y también presenta una dimensión individual y otra colectiva $^{11}$. Desde su dimensión individual abarca todos los daños y perjuicios sufridos por la víctima, y comprende la adopción de medidas individuales relativas al derecho a la restitución, la indemnización, la rehabilitación, la satisfacción y la garantía de no repetición. En su dimensión colectiva, involucra medidas de satisfacción de alcance general como la

7 Ver: RIVERA LLANO, A. La Victimología: ¿Un Problema Criminológico? Editorial Jurídica Radar. Bogotá. 1997. p. 221.

8 Cfr. Sentencia C-412 de 1993. MP. Eduardo Cifuentes Muñoz.

9 Cfr. Sentencia C-275 de 1994. MP. Alejandro Martínez Caballero.

10 Cfr. Principios relativos a una eficaz prevención e investigación de las ejecuciones extrajudiciales, arbitrarias o sumarias, aprobado por el Consejo Económico y Social de las Naciones Unidas, mediante resolución 1989/65 del 29 de mayo de 1989, y ratificado por la Asamblea General mediante resolución 44/162 del 15 de diciembre de 1989. Citados en la sentencia C-293 de 1995.

11 Ver: BUSTOS RAMÍREZ, Juan, et al. Victimología: Presente y futuro. Temis. Bogotá. 1993. p. 156. adopción de medidas encaminadas a restaurar, indemnizar o readaptar los derechos de las colectividades o comunidades directamente afectadas por las violaciones ocurridas ${ }^{12}$.

En sentencia la Corte C- 370 de 2006, refiriéndose al derecho a la reparación de las víctima en los mecanismos de la justicia trasnacional, indicó que esta obligación conllevaba (i) en primer lugar, si ello es posible, la plena restitución (restitutio in integrum), "la cual consiste en el restablecimiento de la situación anterior a la violación"13; (ii) de no ser posible lo anterior, pueden implicar otra serie de medidas que además de garantizar el respecto a los derechos conculcados, tomadas en conjunto reparen la consecuencias de la infracción; entre ellas cabe la indemnización compensatoria.

"4.5.10. El derecho a la verdad implica que en cabeza de las víctimas existe un derecho a conocer lo sucedido, a saber quiénes fueron los agentes del daño, a que los hechos se investiguen seriamente $y$ se sancionen por el Estado, y a que se prevenga la impunidad.

4.5.11. El derecho a la verdad implica para los familiares de la víctima la posibilidad de conocer lo sucedido a ésta, y, en caso de atentados contra el derecho a la vida, en derecho a saber dónde se encuentran sus restos; en estos supuestos, este conocimiento constituye un medio de reparación y, por tanto, una expectativa que el Estado debe satisfacer a los familiares de la víctima y a la sociedad como un todo.

4.5.12. La sociedad también tiene un derecho a conocer la verdad, que implica la divulgación pública de los resultados de las investigaciones sobre graves violaciones de derechos humanos".

La integralidad de la reparación comporta la adopción de todas las medidas necesarias tendientes a hacer desaparecer los efectos de

12 Cfr. Artículo No. 33 del Conjunto de principios para la protección y promoción de los derechos humanos mediante la lucha contra la impunidad.

13 Sentencia de la Corte Interamericana de Derechos Humanos del 15 de junio de 2005. 
las violaciones cometidas, y a devolver a la víctima al estado en que se encontraba antes de la violación.

\section{De las posibilidades de las actuaciones de las victimas en la investigacion y el tramite del juicio oral}

Mediante sentencias de la Corte Constitucional se ha venido reconociendo y construyendo una serie de actuaciones procesales que las victimas pueden reclamar en el proceso penal sin necesidad de postularse en el proceso mediante un apoderado, como sucedía en el proceso inquisitivo de la Ley 600 , que requería presentar una demanda de la parte civil para actuar a través de su abogado en el caso donde la víctima era la principal interesada en las resultas del proceso, en perseguir a su victimario, buscando que se hiciera justicia y se le reconociera en ultimas su derecho por el daño causado con el delito.

\subsection{Derecho a solicitar pruebas}

De nada vale tener unos derechos reconocidos en el proceso penal y hacer parte del mismo sino puede pedir pruebas para sacar adelante sus pretensiones. Este cuestionamiento fue el que se presentó y ocupó la Corte en la sentencia C-454 de 2006; el demandante cuestionaba la constitucionalidad del Artículo 357, donde no se acusa una omisión legislativa, que el actor vincula con el contenido normativo de la disposición demandada, consistente en la exclusión de los representantes de las víctimas de la posibilidad de solicitar pruebas en la audiencia preparatoria. De ello se deriva un trato diferenciado, en cuanto la misma disposición contempla la potestad para la Fiscalía, la defensa y aún el ministerio público, de realizar solicitudes probatorias en el señalado acto procesal, dejando de lado mencionar al derecho de las víctimas para solicitar prueba también.

El artículo en cuestión establece: que durante la audiencia el juez dará la palabra a la Fiscalía y luego a la defensa para que soliciten las pruebas que requieran para sustentar su pretensión.
El juez decretará la práctica de las pruebas solicitadas cuando ellas se refieran a los hechos de la acusación que requieran prueba, de acuerdo con las reglas de pertinencia y admisibilidad previstas en este código.

Las partes pueden probar sus pretensiones a través de los medios lícitos que libremente decidan para que sean debidamente aducidos al proceso $^{14}$.

Excepcionalmente, agotadas las solicitudes probatorias de las partes, si el Ministerio Público tuviere conocimiento de la existencia de una prueba no pedida por éstas que pudiere tener esencial influencia en los resultados del juicio, solicitará su práctica.

Estimó la Corte que, lo primero que debe precisarse, para establecer el alcance de esta norma, es que la audiencia preparatoria constituye, dentro del nuevo sistema, el acto procesal por excelencia para el trámite de las solicitudes de pruebas que habrán de practicarse en el juicio oral. Es la oportunidad procesal ${ }^{15}$ para solicitar las pruebas orientadas a llevar al conocimiento del juez, más allá de toda duda razonable, los hechos y circunstancias materia del juicio, que permitan establecer la responsabilidad penal del acusado como autor o partícipe de esos hechos.

La norma establece las reglas que debe observar el juez respecto de las solicitudes probatorias que se realizan en la audiencia preparatoria. Esas reglas son:

a. Se establece una regla general conforme a la cual los únicos actores procesales que pueden solicitar pruebas en esta audiencia son el fiscal y la defensa.

14 Beristaín, A. "¿La Sociedad/Judicatura Atiende a "Sus" Víctimas/Testigos?" En: 50vo Curso Internacional de Criminología: "Justicia y Atención a Víctimas del Delito". México. 1995. p. 322.

15 Con los eventos excepcionalísimos de la prueba anticipada y las facultades también excepcionales que se atribuyen al Ministerio Público en materia probatoria conforme al inciso final del Artículo 357. 
b. El decreto de pruebas solicitadas está condicionado a que éstas se refieran a los hechos de la acusación, y se adecuen a las reglas de pertinencia y admisibilidad.

c. Los medios de prueba a los que pueden acudir "las partes" para acreditar sus pretensiones deben ser lícitos y debidamente aducidos al proceso.

d. Excepcionalmente, "agotadas las solicitudes probatorias de las partes", el Ministerio Público podrá solicitar la práctica de una prueba no pedida, de la cual tuviere conocimiento y que pudiere tener esencial influencia en los resultados del juicio. Su carácter excepcional deriva de que se trata de la única solicitud probatoria que puede ser tramitada con posterioridad a la audiencia preparatoria, tal como lo prevé el Artículo $374^{16}$.

Con fundamento en el anterior análisis, se tiene que el legislador omitió incluir al representante de las víctimas dentro de las partes o intervinientes con facultad para realizar solicitudes probatorias en la audiencia preparatoria.

La garantía del derecho a acceder a la justicia, en el que se inscriben los derechos a la verdad, a la justicia y a la reparación de las víctimas, se encuentra en una relación directa con el derecho a probar. El derecho a conocer la verdad sobre los hechos que entrañan el agravio a la víctima, está inescindiblemente vinculado con la posibilidad de probar; el derecho a la justicia resulta inconcebible al margen de una posibilidad real de incidir probatoriamente en el esclarecimiento de los hechos y la determinación de responsabilidades; y el derecho a la reparación, cuando se ejerce en el proceso penal, se consolida a partir de la determinación de la responsabilidad por el hecho punible ${ }^{17}$.

$16 \quad$ Artículo 374: "Oportunidad de pruebas. Toda prueba deberá ser solicitada o presentada en la audiencia preparatoria, salvo lo dispuesto en el inciso final del Artículo 357, y se practicará en el momento correspondiente del juicio oral y público".

17 BUSTOS RAMÍREZ, Juan, et al. Victimología: Presente y futuro. Ob. Cit. p. 254.
La dependencia de estos derechos conlleva a que el derecho a aportar y solicitar pruebas en torno al hecho mismo, las circunstancias, la determinación de los autores o partícipes, y la magnitud del daño, se constituya en un presupuesto inexcusable del derecho de las víctimas a acceder efectivamente a la justicia. Resulta inane que se contemple la posibilidad de asistencia de los representantes de las víctimas a la audiencia preparatoria (Art. $355 \mathrm{CPP}$ ), que se exija que en esa diligencia deba estar asistida por un profesional del derecho o estudiante de consultorio jurídico (Art. 137.3 CPP), y paralelamente se le excluya de la posibilidad de realizar solicitudes probatorias, tal como lo establece la norma demandada.

La naturaleza bilateral del derecho a la tutela judicial efectiva, que refiere la Corte Constitucional y también menciona Cafetara Nores ${ }^{18}$, impone que se reconozcan a la víctima garantías de acceso a la justicia similares a las que se reconocen al imputado o acusado ${ }^{19}$.

Con fundamento en lo anterior, la Corte encontró que el Artículo 357 de la Ley 906 incurrió

18 CAFETARA NORES. Derecho de la víctima a la tutela judicial efectiva. Editorial Astrea. Buenos Aires. 2004. p. 134.

19 S 454-06: "Precisa la Corte que no pretende desconocer las especificidades del nuevo sistema en el que se asignan a la Fiscalia unas competencias que propugnan por el restablecimiento del derecho y la reparación integral de la víctima (Art. 250.6 CP); sin embargo ellas no tienen la virtualidad de desplazar a la víctima, cuando en un ejercicio soberano de su derecho de acceso a la justicia, opta por agenciar por su cuenta (a través de su representante) sus intereses dentro del proceso penal. No se suple la exclusión de los representantes de las víctimas de la posibilidad de efectuar solicitudes probatorias en la audiencia preparatoria, con la facultad excepcional que el inciso final de la disposición acusada confiere al Ministerio Público para solicitar, en el juicio, la práctica de una prueba no solicitada en la audiencia preparatoria, y que pudiere tener esencial incidencia en los resultados del juicio. Los intereses que defiende el Ministerio Público en el proceso penal (el orden jurídico, el patrimonio público, o los derechos y garantias fundamentales, Art. 109 CPP), son muy distintos a los intereses que agencia el representante de las victimas, englobados en los derechos a conocer la verdad, a que se haga justicia en su caso, y a obtener reparación". 
en una omisión trascendente para el derecho de acceso de la víctima a la justicia (Art.229 CP), en cuanto obstruye sus posibilidades de efectiva realización de sus derechos a la verdad, a la justicia y a la reparación, y la coloca, de manera injustificada, en una posición de desventaja en relación con otros actores e intervinientes procesales.

De de esta manera se concluye en la jurisprudencia constitucional, en la sentencia comentada ${ }^{20}$,

$20 \quad$ C-454 de de 2006: "Los planteamientos jurídicos que el demandante presento ante la Corte en su libelo se resumen en que los siguientes argumentos:. "El demandante señala que el inciso 2 del Artículo 284, las expresiones "la fiscalía" y "la defensa", empleadas en el inciso segundo del Artículo 344, de las expresiones "la fiscalia" y "la defensa y "las partes" previstas en el Artículo 356, la expresión "a solicitud de las partes" usada en el Artículo 358, la expresión "las partes y el Ministerio público" contenida en el inciso primero del Artículo 359, la expresión "las partes" empleada en el Artículo 378, el Artículo 391, y la expresión "la parte que no está interrogando o el Ministerio Público" utilizada en el Artículo 395 de la Ley 906 de 2004, al omitir la referencia expresa a las victimas, les impiden a éstas solicitar y controvertir pruebas, con lo cual se restringe inconstitucionalmente su derecho a la verdad. 7.2. Lo primero que hay que resaltar es que estas disposiciones establecen, como regla general para su aplicación, el que tales facultades en materia probatoria sean ejercidas por la Fiscalia (Artículos 284, 244 y 356, Ley 906 de 2004), la defensa (Artículos 284, 344, 356, Ley 906 de 2004), las partes (Artículos 344, 356, 358, 359, 391 y 395, Ley 906 de 2004) y excepcionalmente por el Ministerio Público (Artículos 359, 391 y 395, Ley 906 de 2004). De lo cual resulta claro que el legislador omitió incluir a las víctimas dentro de las partes o intervinientes que pueden ejercer tales facultades. En segundo lugar, el ejercicio de las facultades probatorias reguladas en las normas de la Ley 906 de 2004 mencionadas, se presenta en distintas etapas de la actuación procesal, asi: (i) la facultad regulada por el Artículo 284, se refiere a la solicitud y práctica de pruebas anticipadas que se lleva a cabo durante la investigación y antes de la instalación de la audiencia de juicio oral; (ii) la facultad regulada por el Artículo 344 tiene lugar en la audiencia de formulación de la acusación; (iii) las facultades reguladas por los Artículos 356, 358, y 359, se ejercen en la audiencia preliminar; $y$ (iv) la facultad regulada por los Artículos 378, 391 y 395, se presenta en la etapa del juicio. Esta distinción resulta relevante para determinar si las facultades probatorias que pueda tener la víctima para el esclarecimiento de la verdad pueden ser ejercidas directamente por ella (o su apoderado), o si bien, en consideración a los rasgos estructurales $y$ características esenciales del sistema penal con tendencia acusatoria diseñado por el legislador en la Ley 906 de que la omisión que se acusa se presente en los siguientes postulados:

- La norma efectivamente incurre en una omisión que excluye de su presupuesto fáctico a un sujeto que por encontrarse en una situación asimilable a los que la norma contempla, debería subsumirse dentro de ese presupuesto fáctico. En efecto, mientras se prevé la posibilidad de que la Fiscalía, la defensa, y aún el ministerio público, en una fase posterior, formulen solicitudes probatorias, se excluye al representante de las víctimas de esa misma posibilidad.

- No se vislumbra una razón objetiva y suficiente que justifique la exclusión del representante de las víctimas de la posibilidad de ejercer el derecho a formular solicitudes probatorias en la audiencia preparatoria. E1 modelo procesal que la Ley configura considera a la víctima como un "interviniente" (Título IV), al que se le deben garantizar todos los derechos que la Constitución le reconoce, como son el derecho a acceder a la justicia (Art. $229 \mathrm{CP}$ ), con sus derivados de acceso a la verdad, a la justicia y a la reparación, a los que se integra de manera inescindible el derecho a probar.

- Por carecer de una razón objetiva y suficiente, la omisión genera una desigualdad injustificada entre los diferentes actores del proceso, particularmente entre víctima $\mathrm{y}$ acusado, a quienes cobija por igual una concepción bilateral del derecho a la tutela judicial efectiva.

2004, dicha facultad debe ser ejercida de manera indirecta a través del Fiscal. En tercer lugar, las facultades probatorias reguladas por las normas en estudio, se refieren a la solicitud (Artículo 284, Ley 906 de 2004), descubrimiento (Artículo 344, Ley 906 de 2004), exhibición (Artículo 358, Ley 906 de 2004), exclusión, rechazo e inadmisibilidad (Artículo 359, Ley 906 de 2004), práctica (Artículos 284, 391, Ley 906 de 2004) y contradicción de pruebas o elementos materiales probatorios (Artículos 356, 378, 395, Ley 906 de 2004)". 
- La omisión entraña el incumplimiento por parte del legislador del deber de configurar una verdadera "intervención" de la víctima en el proceso penal, particularmente en la audiencia preparatoria, en los términos que se lo impone el Artículo 250.6 de la Carta, en concordancia con los Artículos 29 y 229 de la misma.

En consecuencia, declaró exequible el Artículo 357 de la Ley 906 de 2004, en el entendido que los representantes de las víctimas en el proceso penal, pueden realizar solicitudes probatorias en la audiencia preparatoria, en igualdad de condiciones que la defensa y la Fiscalía. De esta manera, el derecho a pedir y solicitar pruebas es un derecho amplio de las víctimas para hacer valer sus pretensiones en el proceso penal en igualdad de condiciones que la defensa y la Fiscalía.

\subsection{Derecho de la víctima a la información: referencia al archivo de las diligencias y el rechazo a la denuncia}

En orden a satisfacer la garantía de comunicación, la norma establece dos prerrogativas para las víctimas de los delitos, que a su vez involucran correlativos deberes del fiscal: el fiscal debe informar a la víctima sobre los derechos que el orden jurídico le reconoce, información que debe efectuarse "desde el momento mismo en que intervenga"; y el fiscal debe informar a la víctima acerca de las facultades y derechos que puede ejercer para perseguir los perjuicios causados con el injusto, así como de la posibilidad de formular esa pretensión a través del fiscal, en el proceso o directamente en el incidente de reparación integral.

La Corte Constitucional, ha determinado que el instante que los órganos de investigación deben proporcionar información a la víctima sobre sus derechos, es desde el primer momento en que las víctimas entren en contacto con las autoridades. Así se deriva de las sentencias
$\mathrm{C}-1154$ de $2005^{21}$ y C-1177 de $2005^{22}$, en las que se dispuso la comunicación de decisiones de archivo de las diligencias (Art. 79), e inadmisión de la denuncia (Art. 69), respectivamente, a las víctimas o denunciantes a pesar de que las normas no contemplaban de manera explícita tal exigencia.

Al respecto dijo la Corte Constitucional: La decisión de archivo puede tener incidencia sobre los derechos de las víctimas; en efecto, a ellas les interesa que se adelante una investigación previa para que se esclarezca la verdad y se evite la impunidad.

Por lo tanto, como la decisión de archivo de una diligencia afecta de manera directa a las víctimas, dicha decisión debe ser motivada para que éstas puedan expresar su inconformidad a partir de fundamentos objetivos y para que las víctimas puedan conocer dicha decisión. Para garantizar sus derechos, la Corte encuentra que la orden del archivo de las diligencias debe estar sujeta a su efectiva comunicación a las víctimas, para el ejercicio de sus derechos.

Igualmente, se debe resaltar que las víctimas tienen la posibilidad de solicitar la reanudación de la investigación y de aportar nuevos elementos probatorios para reabrir la investigación. Ante dicha solicitud es posible que exista una controversia entre la posición de la Fiscalía y la de las víctimas, y que la solicitud sea denegada. En este evento, dado que se comprometen los derechos de las víctimas, cabe la intervención

$21 \quad$ En esta sentencia se analizaron cargos contra los Artículos 15 (parcial), 16 (parcial), 79, 177 (parcial), 274, 284, 285, 288 (parcial), 291, 306 (parcial), 308 (parcial), 327 (parcial), 337, 383 (parcial), 435, 436, y 455 de la Ley 906 de 2004. El pronunciamiento a que se hace referencia en esta oportunidad se relaciona con la exequibilidad condicionada del Artículo 79 relativo a las condiciones de archivo de las diligencias.

22 En esta sentencia la Corte analizó cargos contra el Artículo 69 (parcial) de la Ley 906 de 2004, sobre los requisitos de la denuncia, de la querella y de la petición especial. En particular se analizó la constitucionalidad de la inadmisión de las denuncias sin fundamento. 
del juez de garantías. Se debe aclarar que la Corte no está ordenando el control del juez de garantías para el archivo de las diligencias sino señalando que cuando exista una controversia sobre la reanudación de la investigación, no se excluye que las víctimas puedan acudir al juez de control de garantías ${ }^{23}$.

Similar exigencia se hace en relación con la comunicación al denunciante de la decisión, motivada, por medio de la cual el órgano de investigación inadmite una demanda sin fundamento (Cfr. C-1177 de 2005).

Se trunca el derecho de acceso a la justicia, a través de una concepción recortada de la garantía de comunicación a la víctima, limitada al momento en que ésta "intervenga" en la actuación penal. No se precisa de una "intervención" en sentido procesal ${ }^{24}$ para que las autoridades de investigación asuman los deberes que impone la garantía de comunicación que se proyecta en dos ámbitos: (i) información acerca de los derechos que el orden jurídico establece para garantizar sus intereses en el proceso penal, y (ii) acceso a la información acerca de las circunstancias en que se cometió el delito, que forma parte del derecho "a saber", el cual se materializa con la posibilidad de acceso al expediente o a las diligencias, desde sus primeros desarrollos. La interconexión e interdependencia que existe entre los derechos a la verdad, a la justicia, y a la reparación exige que la garantía de comunicación se satisfaga desde el primer momento en que las víctimas entran en contacto con los órganos de investigación. Los derechos a la justicia y a la reparación pueden verse menguados si se obstruye a la víctima las posibilidades de acceso a la información desde el comienzo de la investigación a efecto de que puedan contribuir activamente con el aporte

23 Sentencia C-1154 de 2005.

24 El Artículo 340 de la Ley 906 de 2004 establece que en la audiencia de formulación de acusación "se determinará la calidad de víctima, de conformidad con el Artículo 132 de este código. Se reconocerá su representación legal en caso de que se constituya". de pruebas e información relevante sobre los hechos.

En el marco de un sistema de investigación con un mayor componente inquisitivo (Ley $600 \mathrm{de}$ 2000), la Corte había declarado la necesidad de que las víctimas, estuviesen presentes desde las diligencias preliminares, al respecto señaló:

"No permitirle a la parte civil - hoy representantes de las víctimas -actuar durante esta etapa -fase preliminar - o exigir que el acceso al expediente sólo pueda hacerlo mediante un derecho de petición, puede llevar a conculcar definitivamente sus derechos a la verdad a la justicia y a la reparación. Tales limitaciones por lo tanto, constituyen una afectación grave del derecho de acceso a la justicia que tiene la victima de un hecho punible.

En consecuencia, y con el fin de proteger los derechos de la parte civil, la Corte declarará la inexequibilidad de la expresión "a partir de la resolución de apertura de instrucción" contenida en el Artículo 47 de la Ley 600 de 200', como quiera que los derechos a la verdad, a la justicia y a la reparación económica dependen de que en esta etapa se le permita a la parte civil intervenir activamente aportando pruebas y cooperando con las autoridades judiciales y conociendo y controvirtiendo las decisiones que se adopten durante esta etapa, en especial de la providencia mediante la cual se decide no abrir formalmente la investigación"25.

En el sistema actual se establece una fase de indagación e investigación cuyo propósito es el de recaudar elementos materiales de prueba orientados a establecer la existencia de la conducta punible, y los presupuestos que permitan sostener una imputación y posteriormente una acusación. Aunque en esta fase de indagación e investigación, no se practican "pruebas" en sentido formal, sí se recaudan importantes elementos materiales de prueba relacionados con el hecho y la responsabilidad del imputado

25 Sentencia C-228 de 2002, declaró inexequible el Artículo 47 de la Ley 600 de 2000, que restringía el acceso de la parte civil al proceso a partir del momento en que se produjera apertura formal de instrucción. 
o acusado, que deberán ser refrendados en la fase del juicio. Es evidente en consecuencia, que exista un claro interés de las víctimas y perjudicados con la conducta investigada de acceder a la indagación desde sus inicios, a efectos de contribuir positivamente al recaudo del material que dará soporte a la imputación y la acusación, eventos perfectamente compatibles con sus derechos a la verdad, a la justicia y a la reparación.

La Corte se pronunció sobre el derecho de la defensa a intervenir aún antes de la formulación de imputación ${ }^{26}$, lo que marca un umbral para la protección de los derechos de las víctimas a acceder a las diligencias, desde sus inicios, es decir, desde el momento en que entren en contacto con las autoridades, y aún antes de que se hubiese formalizado una "intervención" en sentido jurídico - procesal. La garantía de comunicación de los derechos de las víctimas no se satisface a plenitud, si se produce sólo al momento en que se produce "su intervención"; la misma, para que sea plena, debe producirse desde el momento en que las víctimas entran en contacto con los órganos de investigación.

\subsection{El derecho de las víctimas a un recurso judicial efectivo como consecuencia de una información oportuna}

En la sentencia 454-06 se cuestionó los alcances del Artículo 135, disposición que no consagraba la "Garantía de comunicación a las víctimas"; los aspectos relativos a las facultades y derechos que puede ejercer este interviniente en el proceso, en lo relacionado con su pretensión de verdad y de justicia. La norma reduce tal garantía a la pretensión indemnizatoria ${ }^{27}$.

26 En la sentencia C-799 de 2005, la Corte declaró la constitucionalidad del Artículo $8^{\circ}$ que consagra el derecho defensa del imputado a partir de que adquiriera tal condición, sin perjuicio del ejercicio de su derecho de defensa en la indagación e investigación anterior a la imputación.

27 BERISTAIN, A. Criminología, Victimología y Cárceles. Tomo I. Pontificia Universidad Javeriana. Facultada de Ciencias Jurídicas. Bogotá. 1996. p. 352.
Sobre la efectividad del derecho de las víctimas a un recurso judicial efectivo (CP, Artículos 29 y 229), ha establecido la jurisprudencia que su garantía depende de que éstas puedan intervenir en cualquier momento del proceso penal, aún en la fase de indagación preliminar. Su intervención no sólo está orientada a garantizar la reparación patrimonial del daño inferido con el delito, sino también a la satisfacción de sus derechos a la justicia y a la verdad. En ocasiones, incluso la representación de las víctimas en el proceso penal tiene unos cometidos exclusivamente vinculados al goce efectivo de los derechos a la justicia y la reparación. Bajo estas consideraciones la Corte constitucional estableció una doctrina en la que explícitamente abandonó una concepción reductora de los derechos de las víctimas, fundada únicamente en el resarcimiento económico, para destacar que las víctimas, o los perjudicados con el delito, tienen un derecho efectivo al proceso y a participar en él, con el fin de reivindicar no solamente intereses pecuniarios, sino también, y de manera prevalente, para hacer efectivos sus derechos a la verdad y a la justicia ${ }^{28}$.

En la Sentencia que hacemos referencia, la Corte Constitucional, encontró que el Artículo 135 demandado, omitió la "garantía de comunicación a la víctima" en lo que concierne a las facultades y poderes procesales que se derivan de su derecho a conocer la verdad y a que se haga justicia. El derecho a conocer la verdad, que incorpora el derecho a saber, lo habilita para un acceso pleno a la investigación desde sus inicios, no solamente como tributo a su dignidad que exige una elemental consideración al incremento del dolor que genera la incertidumbre sobre lo acontecido, sino como expresión de su derecho a una tutela judicial efectiva que exige el establecimiento de mecanismos

28 Esta doctrina fue desarrollada tanto en el ámbito de la justicia penal militar, como de la justicia penal ordinaria. Cfr. Sentencias C-293 de 1995; C-163 de 2000; C-1149 de 2001; C-228 de 2002; C-805 de 2002; C-916 de 2002. 
adecuados para que las víctimas puedan obtener el goce efectivo de sus derechos a la justicia y a la reparación integral ${ }^{29}$.

Las omisiones que se imputan al contenido normativo acusado, en efecto plantean un retorno a una concepción de los derechos de las víctimas, que se entendía superada, en cuanto reduce la garantía de comunicación a la víctima tanto en su ámbito temporal, como en su contenido sustancial. En su ámbito temporal por que la limita al momento en que la víctima "interviene" en el proceso, excluyendo tal garantía de momentos previos en que la víctima no ha consolidado una intervención formal, pero ha entrado en contacto con las autoridades de investigación. En cuanto a su contenido sustancial por que restringe, la garantía de comunicación a la pretensión indemnizatoria.

De esta manera se estima que la norma demanda es inconstitucional en cuanto:

- La norma excluye de sus consecuencias situaciones fácticas que deberían estar amparadas por el contenido normativo acusado, como son la aplicación de la garantía de comunicación a fases previas a una "intervención" formal, y respecto de todos los derechos (no solamente la reparación) de que son titulares las víctimas de los delitos.

- No se aprecia una justificación objetiva y suficiente para la exclusión de fases previas a una intervención formal, o de los derechos a la verdad y a la justicia, de la garantía de comunicación que la norma consagra. Por el contrario, el derecho de acceso a la justicia (Art. 229), exige que toda la fase de indagación e investigación esté amparada por la garantía de comunicación a las víctimas sobre sus derechos, y que la misma, se extienda a las prerrogativas y potestades procesales que se derivan de los derechos a la verdad y a la justicia.

RIVERA LLANO, A. La Victimología: ¿Un Problema Criminológico? Ob. Cit. p. 145.
- Al estar desprovistas tales omisiones de una razón objetiva y suficiente, se genera una situación que privilegia de manera injustificada la pretensión indemnizatoria de la víctima, con sacrificio de los derechos de verdad y justicia de que es titular, los cuales han sido reivindicados por la jurisprudencia de esta Corporación. Esta disección en la concepción de los derechos de las víctimas genera a su vez, un desequilibrio en cuanto restringe el alcance de los derechos de las víctimas en el proceso, en contraste con los derechos de otros actores procesales, desvirtuándose así el carácter bilateral del derecho a una tutela judicial efectiva.

- Las omisiones acusadas implican el incumplimiento de un deber constitucional del legislador, quien está obligado a ajustar la configuración de los derechos de participación e intervención de las víctimas en el proceso penal a los principios de acceso al proceso (Art. 229), de todos los actores que participan en el conflicto penal, así como a la concepción integral de los derechos de las víctimas derivada de los Artículos $1^{\circ}, 2^{\circ}$ y 93 de la Carta, en los términos establecidos en esta sentencia.

En consecuencia, la Corte, declaró la constitucionalidad condicionada del Artículo 135 de la Ley 906 de 2004, en el entendido que la garantía de comunicación a la víctima de sus derechos, se realizará desde el momento mismo en que ésta entre en contacto con las autoridades de investigación penal, y que la misma debe referirse a los derechos a la verdad, a la justicia y a la reparación de que es titular.

\subsection{Derecho de las víctimas del delito de desaparición forzada a la no imprescriptibilidad de la acción penal}

En la sentencia C-580 de $2002^{30}$, la Corte estableció que el derecho de las víctimas del delito

30 Sentencia C-580 de 2002. MP. Rodrigo Escobar Gil, con Salvamento Parcial de Voto de los Magistrados Jaime Araujo Rentería y Clara Inés Vargas Hernández. 
de desaparición forzada de personas y la necesidad de garantizar los derechos a la verdad y a la justicia, permitían que el legislador estableciera la imprescriptibilidad de la acción penal, siempre que no se haya identificado e individualizado a los presuntos responsables.

Indicó la Corte Constitucional en la sentencia referenciada que el hecho de establecer la imprescriptibilidad de la acción penal en los delitos de genocidio y desaparición forzada se debe en primer lugar, por el interés en erradicar la impunidad, para lo cual es necesario que la sociedad y los afectados conozcan la verdad, que se atribuyan las responsabilidades individuales e institucionales correspondientes, y en general que se garantice el derecho de las víctimas a la justicia. En segundo lugar, por el derecho de las víctimas a recibir una reparación por los daños. En tercer lugar, debido a la dificultad que suponen la recopilación de las pruebas necesarias y el juzgamiento efectivo de quienes habitualmente incurren en tales conductas.

"El interés en erradicar la impunidad por el delito de desaparición forzada compete a la sociedad en su conjunto. Como ya se dijo, para satisfacer dicho interés es necesario que se conozca toda la verdad de los hechos, y que se atribuyan las responsabilidades individuales e institucionales correspondientes. En esa medida, tanto el interés en que se conozca la verdad, como en que se atribuyan responsabilidades individuales e institucionales por los hechos, sobrepasan el ámbito del interés individual de las víctimas. Por el contrario, constituyen verdaderos intereses generales de carácter prevalente en los términos del Artículo $1^{\circ}$ de la Carta Politica.

En efecto, el conocimiento público de los hechos, el señalamiento de responsabilidades institucionales e individuales y la obligación de reparar los daños causados son mecanismos útiles para crear conciencia entre las personas acerca de la magnitud de los daños causadas por el delito. En esa medida, son también mecanismos de prevención general y especial del delito, que sirven para garantizar que el Estado no apoye, autorice o asuma una actitud aquiescente frente a tales conductas. En general, la acción penal en los casos de desaparición forzada de personas es un mecanismo a través del cual se establecen responsabilidades institucionales que llevan a que el Estado se sujete al derecho en el ejercicio de la fuerza, y a hacer efectivo el deber de las autoridades de protegery garantizar los derechos fundamentales (... $)^{31}$ ".

Sin embargo, sostiene la Corte, que el interés estatal en proteger a las personas contra la desaparición forzada no puede hacer insustancial el derecho a un debido proceso sin dilaciones injustificadas. Por lo tanto, cuando el Estado ya ha iniciado la investigación, ha identificado e individualizado a los presuntos responsables, y los ha vinculado al proceso a través de indagatoria o de declaratoria de persona ausente, la situación resulta distinta. Por un lado, porque en tal evento está de por medio la posibilidad de privarlos de la libertad a través de medios coercitivos, y además, porque no resulta razonable que una vez vinculados al proceso, los acusados queden sujetos a una espera indefinida debida a la inoperancia de los órganos de investigación y juzgamiento del Estado.

$\mathrm{E}$ l interés de la persona vinculada a un proceso penal de definir su situación frente a medidas a través de las cuales el Estado puede privarlo materialmente de la libertad ${ }^{32}$. Por lo anterior, la imprescriptibilidad de la acción penal resulta conforme a la Carta Política, siempre y cuando no se haya vinculado a la persona al proceso a través de indagatoria. Cuando el acusado ya ha sido vinculado, empezarán a correr los términos de prescripción de la acción penal, si el delito está consumado.

\subsection{Derecho a controvertir decisiones que sean adversas a sus derechos}

En la sentencia C-004 de $2003^{33}$ la Corte reconoció el derecho de las víctimas a impugnar

31 Ibídem.

32 MÉNDEZ, J. "Derecho a la verdad frente a las graves violaciones a los Derechos Humanos". Ob. Cit. p. 214.

33 Sentencia C-004 de 2003. MP. Eduardo Montealegre Lynett, en donde la Corte resolvió lo siguiente: 
decisiones tales como las de preclusión de la investigación, de cesación de procedimiento y la sentencia absolutoria. Decisiones favorables al procesado pero que son adversas a los intereses de los ofendidos con el delito.

\section{En esta providencia la Corte}

"concluye entonces que la restricción impuesta por las expresiones acusadas es desproporcionada frente a los derechos de las víctimas, cuando se trata de la impunidad de violaciones a los derechos humanose infracciones graves al derecho internacional humanitario. En esos eventos, los derechos de las víctimas no sólo autorizan sino que exigen una limitación al non bis in idem, a fin de permitir la reapertura de esas investigaciones, si surge un hecho o prueba nueva no conocida al tiempo de los debates procesales. Era entonces necesario que la Ley previera esa hipótesis al regular las causales de revisión, por lo que la Corte deberá condicionar el alcance de las expresiones acusadas en ese aspecto" ${ }^{\text {"34. }}$.

"Declarar EXEQUIBLE el numeral $3^{\circ}$ del Artículo 220 de la Ley 600 de 2000 o Código de Procedimiento Penal, en el entendido de que, de conformidad con los fundamentos 31, 36 y 37 de esta sentencia, la acción de revisión por esta causal también procede en los casos de preclusión de la investigación, cesación de procedimiento y sentencia absolutoria, siempre $y$ cuando se trate de violaciones de derechos humanos o infracciones graves al derecho internacional humanitario, y un pronunciamiento judicial interno, o una decisión de una instancia internacional de supervisión y control de derechos humanos, aceptada formalmente por nuestro pais, haya constatado la existencia del hecho nuevo o de la prueba no conocida al tiempo de los debates. Igualmente, y conforme a lo señalado en los fundamentos 34, 35 y 37 de esta sentencia, procede la acción de revisión contra la preclusión de la investigación, la cesación de procedimiento y la sentencia absolutoria, en procesos por violaciones de derechos humanos o infracciones graves al derecho internacional humanitario, incluso si no existe un hecho nuevo o una prueba no conocida al tiempo de los debates, siempre y cuando una decisión judicial interna o una decisión de una instancia internacional de supervisión y control de derechos humanos, aceptada formalmente por nuestro país, constaten un incumplimiento protuberante de las obligaciones del Estado colombiano de investigar en forma seria e imparcial las mencionadas violaciones".

34 Ibídem: "Sin embargo, la Corte recuerda que en todo caso la seguridad jurídica, la fuerza de la cosa juzgada, y la protección contra el doble enjuiciamiento, son valores de
En consideraciones de la Corte, la impunidad de las violaciones a los derechos humanos y al derecho humanitario es más grave, cuando el Estado ha incumplido en forma protuberante con sus deberes de investigar y sancionar seriamente esos delitos. En esos eventos, la preponderancia de los derechos de las víctimas y de la búsqueda de un orden justo sobre la seguridad jurídica y el non bis in ídem es aún más evidente, por las siguientes dos razones:

- Para las víctimas y los perjudicados por una violación a los derechos humanos, la situación resulta aún más intolerable, pues su dignidad humana es vulnerada en cierta medida doblemente, ya que esas personas no sólo fueron lesionadas por un comportamiento atroz sino que, además, deben soportar la indiferencia del Estado, quien incumple en forma protuberante con su obligación de esclarecer esos actos, sancionar a los responsables y reparar a los afectados.

- Una posible revisión de aquellos procesos en que el Estado, en forma protuberante, dejó de lado su deber de investigar seriamente esas violaciones a los derechos humanos, no impacta en forma muy intensa la seguridad

rango constitucional, que ameritan una especial protección jurídica, y por ello la sentencia integradora que sea proferida debe prever también garantías a fin amparar en forma suficiente esos valores constitucionales. Es pues indispensable que el ordenamiento impida la reapertura caprichosa de procesos que habian hecho tránsito a cosa juzgada. Ciertas cautelas y protecciones formales en beneficio del procesado resultan entonces imprescindibles.

En tal contexto, esta Corporación considera que en los casos de negligencia protuberante del Estado en brindar justicia a las victimas de violaciones a los derechos humanos y al derecho internacional humanitario, para que proceda la revisión, sin que aparezca un hecho nuevo o una prueba no conocida al tiempo del proceso, es necesario que exista una declaración de una instancia competente que constate que el Estado incumplió en forma protuberante con la obligación de investigar seriamente esa violación. A fin de asegurar una adecuada protección a la persona absuelta, la constatación de esa omisión de las autoridades deberá ser adelantada por un organismo imparcial e independiente, y por ello, en el plano interno, dicha declaración sólo puede ser llevada a cabo por una autoridad judicial". 
jurídica, por la sencilla razón de que en esos procesos las autoridades realmente no realizaron una investigación seria e imparcial de los hechos punibles. Y por ende, precisamente por ese incumplimiento del Estado de adelantar seriamente la investigación, la persona absuelta en realidad nunca estuvo seriamente procesada ni enjuiciada, por lo que una reapertura de la investigación no implica una afectación intensa del non bis in ídem ${ }^{35}$.

Es pues claro que en los casos de impunidad de violaciones a los derechos humanos o de infracciones graves al derecho internacional humanitario derivadas del incumplimiento protuberante por el Estado colombiano de sus deberes de sancionar esas conductas, en el fondo prácticamente no existe cosa juzgada, pues ésta no es más que aparente. En esos eventos, nuevamente los derechos de las víctimas desplazan la garantía del non bis in ídem, y por ello la existencia de una decisión absolutoria con fuerza formal de cosa juzgada no debe impedir una reapertura de la investigación de esos comportamientos, incluso si no existen hechos o pruebas nuevas, puesto que la cosa juzgada no es más que aparente.

La restricción prevista por las expresiones acusadas es desproporcionada frente a los derechos de las víctimas y al deber de las autoridades de lograr la vigencia de un orden justo, cuando la impunidad de las violaciones a los derechos humanos y las afectaciones graves al derecho internacional humanitario deriva del claro incumplimiento del Estado de su obligación de investigar, de manera seria e imparcial, esos crímenes. En esos eventos, incluso si no existe un hecho o prueba nueva, los derechos de las víctimas también exigen una limitación al non bis in ídem, a fin de permitir la reapertura de esas investigaciones, pues la cosa juzgada de la que gozaba la persona absuelta no era más

35 Ver: Sentencia C-004 de 2003. M.P. Eduardo Montealegre Lynett. que aparente, ya que en el fondo, debido a las omisiones protuberantes del Estado, no existió realmente un proceso contra ese individuo ${ }^{36}$. Era entonces necesario que la Ley previera la posibilidad de reabrir las investigaciones por violaciones a los derechos humanos y por graves afectaciones al derecho internacional humanitario en aquellos casos en que con posterioridad a la absolución se muestre que dicha absolución deriva de una omisión protuberante del deber del Estado de investigar, en forma seria e imparcial, esos comportamientos. Ahora bien, el Artículo 220 del CPP, que regula las causales de revisión, no prevé esa hipótesis, pues no siempre esa omisión protuberante de las obligaciones estatales puede ser atribuida a una conducta típica del juez o de un tercero, o a la existencia de una prueba falsa, que son los casos en donde el estatuto procesal penal autoriza la acción de revisión contra decisiones absolutorias con fuerza de cosa juzgada. Existe entonces una omisión legislativa en este punto, que requiere una sentencia integradora, que autorice la acción de revisión en esos casos, a fin de proteger los derechos de las víctimas de violaciones a los derechos humanos y violaciones graves al derecho internacional humanitario.

La garantía establecida en la sentencia C-004 de $2003^{37}$, fue recogida en la sentencia C-046 de $2004^{38}$, cuando la Corte protegió el derecho de

36 Ver: Sentencia C-370 de 2006.

37 MP: Eduardo Montealegre Lynett

38 Sentencia C-046 de 2006. MP. Rodrigo Escobar Gil, en donde la Corte se pronuncia sobre la constitucionalidad de la expresión "absolutoria", contenida en el inciso $3^{\circ}$ del Artículo 176 y en el numeral $1^{\circ}$ del Artículo 177 de la Ley 906 de 2004, cuestionada porque supuestamente violaba la garantía del non bis ibídem a favor del procesado. La Corte declara la exequibilidad de los apartes demandados y señala que la posibilidad de impugnar la sentencia absolutoria en el proceso penal regulado por la Ley 906 de 2004, no sólo no viola el principio del non bis ibídem sino que es además una de las garantías a los derechos de las víctimas. La Corte resolvió: Declarar la EXEQUIBILIDAD, por los cargos estudiados, de la expresión "absolutoria", contenida en el inciso $3^{\circ}$ del 
las víctimas del delito a impugnar la sentencia absolutoria.

Es decisión al pronunciarse en sede de constitucionalidad con ocasión de una demanda de inconstitucionalidad presentada contra la posibilidad de interponer el recurso de casación frente a las sentencias absolutorias en materia penal, la Corte señaló que

“...si, se accediera a la petición hecha por el actor en el sentido de descartar la procedencia de la casación en las circunstancias que él invoca y por tanto no se permitiera al Ministerio Público, a la Fiscalía, a la victima, o a los perjudicados con el hecho punible solicitar la casación de la sentencia absolutoria con el fin de que se corrija un eventual desconocimiento de la Constitución y la Ley, se estaría no solo desconociendo el derecho a la igualdad de dichos intervinientes en el proceso penal sino su derecho al acceso a la administración de justicia en perjuicio de los derechos del Estado, de la sociedad, de la víctima o de los eventuales perjudicados con el hecho punible y con grave detrimento de los derechos a la verdad a la justicia y a la reparación ${ }^{\prime 39}$.

Artículo 176 y en el numeral $1^{\circ}$ del Artículo 177 de la Ley 906 de 2004.

39 Ver Sentencia C-228 de 2002. MP. Manuel José Cepeda Espinosa y Eduardo Montealegre Lynett. En dicha sentencia se hicieron las siguientes consideraciones que resulta pertinente recordar "(t)anto en el derecho internacional, como en el derecho comparado y en nuestro ordenamiento constitucional, los derechos de las víctimas y perjudicados por un hecho punible gozan de una concepción amplia -no restringida exclusivamente a una reparación económica - fundada en los derechos que ellas tienen a ser tratadas con dignidad, a participar en las decisiones que las afecten y a obtener la tutela judicial efectiva del goce real de sus derechos, entre otros, y que exige a las autoridades que orienten sus acciones hacia el restablecimiento integral de sus derechos cuando han sido vulnerados por un hecho punible. Ello sólo es posible si a las víctimas y perjudicados por un delito se les garantizan, a lo menos, sus derechos a la verdad, a la justicia y a la reparación económica de los daños sufridos. De tal manera que la víctima y los perjudicados por un delito tienen intereses adicionales a la mera reparación pecuniaria. Algunos de sus intereses han sido protegidos por la Constitución de 1991 y se traducen en tres derechos relevantes para analizar la norma demandada en el presente proceso: 1. El derecho a la verdad, esto es, la posibilidad de conocer lo que sucedió y en buscar una coincidencia entre
Mutatis Mutandis, tales consideraciones resultan aplicables a la posibilidad de apelar la sentencia penal absolutoria ${ }^{40}$.

La Corte llega a la conclusión de que, no solo no es violatorio del non bis in idem, establecer la posibilidad de apelar la sentencia absolutoria, sino que, por el contrario, excluir esa posibilidad podría resultar problemático desde la perspectiva de la garantía constitucional de la doble instancia, el derecho de acceso a la administración de justicia, los derechos de las víctimas a la verdad, la justicia y la reparación y el imperativo que la Carta impone a las autoridades de lograr la vigencia de un orden justo (Art. $2^{\circ} \mathrm{CP}$ ).

De esta manera se puede estimar que el legislador colombiano garantiza la posibilidad del sindicado de impugnar la sentencia condenatoria, también se ha previsto, en desarrollo de la garantía de la doble instancia, la posibilidad de apelar la sentencia absolutoria, lo cual constituye una garantía para las víctimas y protege el interés de la sociedad en una sentencia que, con pleno respeto de los derechos del sindicado, conduzca a la verdad, la reparación y la justicia ${ }^{41}$.

Sobre este punto, la Corte ha reiterado que, el debido proceso se predica no solo respecto de los derechos del acusado sino de los de todos los intervinientes en el proceso penal, a quienes, junto al derecho al debido proceso, debe garantizárseles el derecho también superior de la eficacia del acceso a la justicia (Art. 229 $\mathrm{CP})^{42}$.

la verdad procesal y la verdad real. Este derecho resulta particularmente importante frente a graves violaciones de los derechos humanos. 2. El derecho a que se haga justicia en el caso concreto, es decir, el derecho a que no haya impunidad. 3. El derecho a la reparación del daño que se le ha causado a través de una compensación económica, que es la forma tradicional como se ha resarcido a la víctima de un delito".

40 Sentencia C-998 de 2004. MP. Álvaro Tafur Galvis.

41 Ver: T-1267 de 2001 y C-282 de 2002.

42 Ver: entre otras, las Sentencias C-648 de 2001 MP. Marco Gerardo Monroy Cabra y C-154 de 2004 MP. Álvaro Tafur Galvis. 
La Corte Constitucional ha concluido que la Carta de 1991 reconoce a las víctimas y perjudicados por un hecho punible unos derechos que desbordan el campo de la reparación económica, pues incluyen también el derecho a la verdad y a que se haga justicia. En ese contexto, si bien la impugnación de la sentencia condenatoria es un derecho consagrado expresamente a favor del sindicado en la Constitución y en diversos instrumentos internacionales, no es menos cierto que la posibilidad de apelar la sentencia absolutoria es expresión de derechos de similar entidad de las víctimas y materialización del deber de las autoridades de asegurar la vigencia de un orden justo ${ }^{43}$.

En el mismo sentido dentro del nuevo sistema, en la sentencia C-979 de $2005^{44}$, la Corte

43 Ver: sentencias C-740 de 2001, C-1149 de 2001, SU1184 de 2001, T-1267 de 2001 y C-282 de 2002.

44 C-979 de 2005, MP. Jaime Córdoba Triviño, con Aclaración de Voto del Magistrado Jaime Araujo Rentería. Expresó la Corte: "Las mismas cautelas que en su momento tuvo la Corte para autorizar la posibilidad de que por la vía de la revisión penal extraordinaria, se reabrieran procesos por violaciones de derechos humanos, que habia culminado con una decisión favorable al sentenciado, con ruptura del principio del non bis in idem, operan en el caso de la reapertura de procesos culminados con sentencia condenatoria. Esas cautelas, orientadas a la preservación del non bis in idem, para los delitos en general, se encuentran explicitas en la regla que contiene la expresión demandada, en cuanto que la reapertura se produce a través de un mecanismo procesal extraordinario, opera para la criminalidad con mayor potencialidad ofensiva y desestabilizadora como son los crimenes contra los derechos humanos y el derecho internacional humanitario, y está condicionada al pronunciamiento de una instancia internacional acerca del incumplimiento del Estado de sus obligaciones de investigación y sanción de estos crímenes. El sentido de la causal, una vez excluida la expresión demandada, deja asi a salvo el principio del non bis in idem para los delitos en general, tal como lo ha establecido la Corte en el pronunciamiento referido. 223. De otra parte, tampoco puede perderse de vista en este análisis, que la extensión de la procedencia de la revisión a los fallos condenatorios en las hipótesis que contempla la causal, atiende también el derecho del sentenciado a un debido proceso y propugna por el establecimiento de un orden justo, por cuanto no resulta legítimo mantener la cosa juzgada en eventos en que una instancia internacional, en desarrollo de competencias reconocidas por el Estado colombiano, declaró que la investigación que dio lugar a la condena no fue seria protegió el derecho de las víctimas a solicitar la revisión extraordinaria de las sentencias condenatorias en procesos por violaciones a derechos humanos o infracciones graves al derecho internacional humanitario, cuando una instancia internacional haya concluido que dicha condena es aparente o irrisoria.

\subsection{Derecho de las victimas en los mecanismos de justicia transicional. Derecho a evitar la impunidad}

En la sentencia C-370 de $2006^{45}$, sobre la revisión de la Ley de Justicia y Paz, la Corte se pronunció sobre los derechos de las víctimas en procesos propios de la justicia transicional. La Corte expreso:

"Al derecho de las víctimas a la protección judicial de los derechos humanos, mediante el ejercicio de

ni imparcial. "24. Encuentra asi la Corte que el alcance que la expresión demandada le imprime a la causal de revisión de la cual forma parte, entraña en primer término, una violación de la Constitución en virtud del desconocimiento de claros referentes internacionales aplicables a la materia por concurrir a integrar el bloque de constitucionalidad (Art. 93 $C P$ ); en segundo término, una actuación contraria al deber constitucional de protección de los derechos de las víctimas de estos delitos que desconocen la dignidad humana y afectan condiciones básicas de convivencia social, necesarias para la vigencia de un orden (Artículo 2 CP); en tercer lugar, un desconocimiento de los compromisos internacionales del Estado colombiano de colaborar con la vigencia de los derechos humanos y sancionar las conductas que afectan estos valores supremos del orden internacional, que nuestro país ha reconocido como elementos esenciales de las relaciones internacionales ( $C P$ Art. $9^{\circ}$ ); y en cuarto lugar una violación al debido proceso de la persona condenada en una actuación que desatiende los deberes constitucionales e internacionales de investigar seria e imparcialmente estos crimenes, aspecto que ha sido constado por una instancia internacional. Por ello, la Corte declarará la inexequibilidad de la expresión acusada que hace parte del Artículo 192.4 de la Ley 906 de 2004".

45 Sentencia C-370 de 2006. MP. Manuel José Cepeda Espinosa, Jaime Córdoba Triviño, Rodrigo Escobar Gil, Marco Gerardo Monroy Cabra, Álvaro Tafur Galvis, Clara Inés Vargas Hernández, con salvamento de voto del magistrado Jaime Araujo Rentería, Alfredo Beltrán Sierra y Humberto Antonio Sierra Porto, en donde la Corte se pronunció sobre la exequibilidad de varias disposiciones de la Ley de justicia y paz, que restringían sus derechos. 
un "recurso sencillo y eficaz", en los términos de los Artículos 8 y 25 de la Convención Americana de Derechos Humanos, corresponde el correlativo deber estatal de juzgar y sancionar las violaciones de tales derechos. Este deber puede ser llamado obligación de procesamiento y sanción judicial de los responsables de atentados en contra de los derechos humanos internacionalmente protegidos.

El deber estatal de investigar, procesar y sancionar judicialmente a los autores de graves atropellos contra el Derecho Internacional de los Derechos Humanos no queda cumplido por el sólo hecho de adelantar el proceso respectivo, sino que exige que este se surta en un "plazo razonable". De otra manera no se satisface el derecho de la víctima o sus familiares a saber la verdad de lo sucedido y a que se sancione a los eventuales responsables" ${ }^{\prime 4}$.

En esta oportunidad la Corte se refirió a la impunidad como "la falta en su conjunto de investigación, persecución, captura, enjuiciamiento y condena de los responsables de las violaciones de los derechos protegidos por la Convención Americana". Afirmó el deber del Estado Colombiano de prevenir la impunidad, toda vez que propicia la repetición crónica de las violaciones de derechos humanos y la total indefensión de las víctimas y de sus familiares. En tal virtud están obligados a investigar de oficio los graves atropellos en contra de los derechos humanos, sin dilación y en forma seria, imparcial y efectiva ${ }^{47}$.

En este sentido, la obligación estatal de iniciar de oficio las investigaciones en caso de graves atropellos en contra de los derechos humanos indica que la búsqueda efectiva de la verdad corresponde al Estado ${ }^{48}$, y no depende de la iniciativa procesal de la víctima o de sus familiares, o de su aportación de elementos probatorios.

\footnotetext{
46 Ibidem.

47 Ibidem.

48 BERISTAIN, A. Criminología y Victimología. Alternativas Re-creadoras al Delito. Leyer. Bogotá. 1998.
}

\section{CONCLUSIONES}

Las actuaciones de las víctimas, según la jurisprudencia de la Corte Constitucional, en el procedimiento penal hacen referencia a los siguientes derechos que se pretenden sean reconocidos como sujeto procesal, estos derechos en su contenido hace referencia a:

- El derecho a la justicia implica que toda víctima tenga la posibilidad de hacer valer sus derechos beneficiándose de un recurso justo y eficaz, principalmente para conseguir que su agresor sea juzgado, obteniendo su reparación.

- Al derecho a la justicia corresponde el deber estatal de investigar las violaciones, perseguir a sus autores $y$, si su culpabilidad es establecida, de asegurar su sanción.

- Dentro del proceso penal las víctimas tienen el derecho de hacerse parte para reclamar su derecho a la reparación.

- En todo caso, las reglas de procedimiento deben responder a criterios de debido proceso.

- La prescripción de la acción penal o de las penas no puede ser opuesta a los crímenes graves que según el derecho internacional sean considerados crímenes contra la humanidad ni correr durante el período donde no existió un recurso eficaz.

- El cuanto a la disminución de las penas, las "Leyes de arrepentidos" son admisibles dentro de procesos de transición a la paz, se "pero no deben exonerar totalmente a los autores".

- La reparación tiene una dimensión doble (individual y colectiva) y en el plano individual abarca medidas de restitución, indemnización y readaptación.

- En el plano colectivo, la reparación se logra a través de medidas de carácter simbólico o de otro tipo que se proyectan a la comunidad. 
- Dentro de las garantías de no repetición, se incluye la disolución de los grupos armados acompañada de medidas de reinserción.

\section{BIBLIOGRAFÍA}

ALZATE, N. El Fenómeno de las Desapariciones Forzada. Tesis de Grado Universidad Nacional de Colombia. Facultad de Derecho. Bogotá. 1989.

AMNISTÍA INTERNACIONAL (S.F.). Manual Para La Acción, Desapariciones Forzadas y Homicidios Políticos: La Crisis de Los Derechos Humanos. EDAI. Madrid.

AMSTRONG, S. (s.f.). Pinochet; Is a Terrorist Hiding in Chile's Senate?. [Citado 7 Ago] Disponible en: http://www.izquierda-unida.es/ Derechos

ASFADDES. Veinte Años de Historia y Lucha. Rodríguez Quito Editores. Bogotá. 2003.

BALDÓ LAVILLA, Francisco. Observaciones metodológicas sobre la construcción de la teoría del delito. Universidad de Barcelona. Barcelona. 1999.

BARNETT, R. (1981) "Restitution a New Paradigm of Criminal Justice". En: GAVIRIA, V. Algunos Aspectos Civiles Dentro del Proceso Penal. Editorial Universidad Externado de Colombia. Bogotá. 1999.

BERISTAIN, A. Criminología y Victimología. Alternativas Re-creadoras al Delito. Leyer. Bogotá. 1998

Criminología, Victimología y Cárceles.

Tomo I. Pontificia Universidad Javeriana. Facultada de Ciencias Jurídicas. Bogotá. 1996.

. "¿La Sociedad/Judicatura Atiende a "Sus" Víctimas/Testigos?" En: 50vo Curso Internacional de Criminología: "Justicia y Atención a Victimas del Delito”. México. 1995.

Información informal. Mensaje informal enviado por correo electrónico. Octubre 20, 2003.
BERISTAIN, C, et al. Afirmación y Resistencia, La Comunidad Como Apoyo. Virus Editorial. Barcelona. 1993.

BOTERO, R. "La Desaparición Forzada". En: Revista Su Defensor. Año 3. No. 25. Agosto 1995

BRIGHT, Ch. Mediación entre Victima y delincuente. 1997. Disponible en: http://www. restorativejustice. org.

BROOKERS, D. Evaluating Restorative Justice Programs. United Nations Crime Congreso. Vienna, Austria. 2000.

BUSTOS RAMÍREZ, Juan, et al. Victimología: Presente y futuro. Temis. Bogotá. 1993.

CAFETARA NORES. Derecho de la víctima a la tutela judicial efectiva. Editorial Astrea. Buenos Aires. 2004.

Ley 906 de 2004.

MÉNDEZ, J. "Derecho A La Verdad Frente A Las Graves Violaciones A Los Derechos Humanos". En: ABREGU, Martín, et al (comp). La Aplicación de los Tratados sobre Derechos Humanos por los Tribunales Locales. Editorial Del Puerto. Buenos Aires. 1997.

"The Right to Truth". En: JOYNER, Christopher C. Ed. Reigning in Impunity for International Crimes and Serious Violations of Fundamental Rights: Proceedings of The Siracusa Conference, 17-21 September, 1998.

MESSUTI, Ana. El tiempo como pena y otros escritos. Criminología y Victimología 2. Pontificia Universidad Javeriana. Facultad de Ciencias Jurídicas. Bogotá. 1998.

MINOW, Martha. "Between Vengance And Forgivness: South Africa Truth And Reconciliation Commission". En: Negotiation Juornal. October. 1998.

MIR PUIG, Santiago. Derecho Penal, Parte General. $4^{\text {a }}$ Edición. Barcelona, 1996.

ORENTLICHER, Diane. Actualización de los principios del "Conjunto de Principios para la 
protección y promoción de los derechos humanos mediante la lucha contra la impunidad". Anexo del Informe final del Relator Especial acerca de la cuestión de la impunidad de los autores de violaciones de los derechos humanos. E/CN.4/Sub2/1997/20/Rev.1. Presentado a la Comisión de Derechos Humanos en 1998. Estos principios fueron actualizados por la experta independiente Diane Orentlicher, de acuerdo con informe E/CN. 4/2005/102, presentado a la Comisión de Derechos Humanos.

RESTREPO, J. "La espada desenvainada". En: Diario El Colombiano. Medellín. Julio 31. 2003.

RESTREPO, L. "Ley de alternatividad penal". En: Diario El Espectador. [Citado 15 Sep. 2003] Disponible en: http://www.elespectador. com/2003/200330907/opinion/nota10.htm.

RICOEUR, P. "¿Quién es el sujeto de derecho?" En: Lo Justo. Colección Espirit. Caparrós Editores. Madrid. 1999.

"E1 concepto de responsabilidad. Ensayo de un análisis semántico". En: Lo Justo. Colección Espirit. Caparrós Editores. Madrid, 1999.

RIVERA LLANO, A. La Victimología: ¿Un Problema Criminológico? Editorial Jurídica Radar. Bogotá. 1997.

\section{SENTENCIAS}

Corte Interamericana de Derechos Humanos del 15 de junio de 2005.

C-412 de 1993. MP. Eduardo Cifuentes Muñoz

C-275 de 1994. MP. Alejandro Martínez Caballero.

C-293 de 1995. MP. Carlos Gaviria Díaz.
C-163 de 2000.

C-648 de 2001 MP. Marco Gerardo Monroy Cabra.

C-740 de 2001.

C-1149 de 2001.

C-228 de 2002. MP. Manuel José Cepeda Espinosa y Eduardo Montealegre Lynett.

C-282 de 2002.

C-580 de 2002. MP. Rodrigo Escobar Gil, con Salvamento Parcial de Voto de los Magistrados Jaime Araujo Rentería y Clara Inés Vargas Hernández.

C-805 de 2002.

C-916 de 2002.

C-004 de 2003. MP. Eduardo Montealegre Lynett.

C-154 de 2004 MP. Álvaro Tafur Galvis.

C-799 de 2005.

C-979 de 2005. MP. Jaime Córdoba Triviño.

C-998 de 2004. MP. Álvaro Tafur Galvis.

C-1154 de 2005.

C-046 de 2006. MP. Rodrigo Escobar Gil.

C-370 de 2006. MP. Manuel José Cepeda Espinosa, Jaime Córdoba Triviño, Rodrigo Escobar Gil, Marco Gerardo Monroy Cabra, Álvaro Tafur Galvis, Clara Inés Vargas Hernández.

C-454 de 2006.

S 454 de 2006.

SU-1184 de 2001.

T-443 de 1994. MP. Eduardo Cifuentes Muñoz.

T-1267 de 2001. 